\title{
CARACTERÍSTICAS CULTURAIS NACIONAIS EM ORGANIZAÇÕES INDUSTRIAIS DO SETOR ALIMENTÍCIO PARANAENSE
}

\author{
Patricia Tendolini Oliveira ${ }^{\mathrm{i}}$ \\ Clóvis L. Machado-da-Silva ${ }^{\mathrm{ii}}$
}

RESUMO

No presente estudo procura-se ampliar a compreensão do fenômeno organizacional no Brasil, mediante a análise do nível de presença dos principais traços culturais nacionais nos diferentes estágios do ciclo de vida das empresas do setor alimentício no Estado do Paraná. Os resultados permitem afirmar que, para o conjunto das empresas pesquisadas, o nível de presença das características culturais personalismo, protecionismo/orientação pela autoridade externa, formalismo, receptividade positiva e orientação para o curto prazo varia de acordo com o estágio do ciclo de vida em que se encontram as organizações objeto da investigação, corroborando a hipótese básica da pesquisa. Já no que concerne às características protecionismo/postura de espectador, aversão à incerteza, jeitinho e receptividade negativa não se verificou a corroboração estatística da hipótese básica do estudo.

ABSTRACT

In order to better understand the organizational phenomenon in Brazil, this research analyzed the variation of the presence of the main Brazilian cultural traits in the different life cycle stages in the companies of the food industry in the State of Paraná. The results indicate that, among the companies under study, personalism, protectionism/orientation by external authority, formalism, positive receptivity and short-term orientation are characteristics that vary according to the organizational life cycle stage; so all of them corroborate the basic research hypothesis. On the other hand, protectionism/spectator's posture, aversion to uncertainty, jeitinho, and negative receptivity did not show statistical significance to the hypothesis testing.

\section{INTRODUÇÃO}

O surgimento do que se rotula como sociedade organizacional e a instauração do mito racional revelam a organização burocrática como modelo social fundamental das sociedades urbanoindustriais e a racionalidade instrumental como padrão dominante dos tempos modernos (Presthus, 1962, 1978; Guerreiro Ramos, 1981; Bowles, 1997; Dellagnelo e Machado-da-Silva, 2000). Assim, a compreensão da sociedade moderna reporta-se ao processo historicamente construído de secularização do mundo (Weber, 1991). De acordo com o esquema conceitual weberiano, as interpretações mágicas da realidade, predominantes na sociedade tradicional, dão lugar à racionalidade formal, característica marcante da sociedade moderna (Kalberg, 1980). A trajetória é, pois, do dogma religioso para o dogma racional - entendido como lógica de ação que se sustenta em relações meio-fim com cálculo utilitário de conseqüências.

\footnotetext{
i Pesquisadora Assistente do Núcleo de Pesquisa em Organizações - NPO do Centro de Pesquisa e Pós-Graduação em Administração da Universidade Federal do Paraná.

ii Professor Titular e Coordenador do Núcleo de Pesquisa em Organizações - NPO do Centro de Pesquisa e PósGraduação em Administração da Universidade Federal do Paraná. Pesquisador 1 -A do CNPq.
} 
O dogma racional não se restringe ao domínio da esfera econômica, mas invade, de forma crescente, todas as esferas da sociedade moderna: o Estado, as organizações de produção e de disseminação de conhecimentos, as religiões, as artes, o lazer e, até mesmo, a família. Cabe ressaltar, no entanto, que o processo de racionalização do mundo realiza-se sobre a base sociocultural de cada sociedade tradicional existente, o que leva ao imbricamento, mais ou menos temporário, do novo com o velho, do moderno com o tradicional. Dessa forma, sobrevivem, em cada sociedade, características culturais tradicionais que atuam como fatores limitadores do pleno domínio da racionalidade formal.

No caso da sociedade brasileira, destaca-se a existência de traços culturais que foram construídos ao longo de sua história e que continuam presentes, com maior ou menor intensidade, até os dias atuais, tais como o jeitinho, o formalismo e o personalismo. Guerreiro Ramos (1966) e Castor (2000), por exemplo, afirmam que o esquema da burocracia dominante no Brasil é patrimonialista, em que se encontram vivos, de forma acentuada, o nepotismo, o clientelismo e o corporativismo. Tal assertiva parece aplicar-se de maneira mais incisiva no segmento das organizações públicas.

As características culturais decorrentes da formação da sociedade brasileira são marcantes e consideradas, até mesmo, como elementos fundamentais da identidade nacional. É de se esperar, portanto, a manifestação desses traços nas organizações formais, cujo modelo orientador básico é o burocrático, em face da dinâmica de racionalização em processo. Nessas organizações, enquanto participantes de uma ordem societária maior, a sociedade global, também se torna evidente a tendência de modernização e de uniformização das estruturas e dos sistemas administrativos e operacionais. Observa-se, assim, um processo de mútua influência e constituição: características culturais se manifestam nas organizações que, simultaneamente, sofrem a pressão modernizadora do movimento em direção à crescente racionalização das estruturas e dos processos de trabalho.

Tendo em vista que as organizações diferem em grau de complexidade, desde estruturas mais simples até estruturas mais elaboradas, pode-se considerar que elas se encontram em diferentes estágios do processo de racionalização. Desse modo, à medida que as organizações se tornam mais complexas, sofrendo alterações em suas dimensões estruturais em direção à profissionalização e à modernização, é razoável supor certa tendência de declínio na presença das características culturais tradicionais no âmbito organizacional. Nesse sentido, a visão metafórica de ciclo de vida, a partir da qual o fenômeno organizacional é analisado sob perspectiva dinâmica, em que se observa a ocorrência de mudanças estruturais nas organizações em diferentes estágios, parece propiciar um indicador concreto do grau de racionalização das atividades e procedimentos organizacionais. É pressuposto básico dos autores do presente estudo, que a presença de características culturais nacionais, refletidas nas organizações, de maneira geral sinalize tendência de declínio à medida que as organizações se situem em estágios mais elaborados do ciclo de vida.

Â luz das breves considerações precedentes, este artigo está estruturado, na seqüência, da forma como se segue: uma seção destinada a estabelecer o quadro teórico de referência do estudo, onde se abordam, em especial, as características culturais brasileiras e o conceito de ciclo de vida organizacional; outra, em que se apresenta a situação em estudo, classificando, primeiramente, as empresas de acordo com o estágio do ciclo de vida em que se encontram e, após, verificando o nível de presença das características culturais nacionais mais ressaltadas na literatura especializada sobre o tema; por último, à guisa de conclusão, uma seção de considerações finais.

\section{QUADRO TEÓRICO DE REFERÊNCIA}

O estudo da cultura no âmbito das organizações formais tem se circunscrito, predominantemente, ao que se denomina cultura organizacional. No entanto, além desse foco de análise, é importante considerar as características culturais nacionais que as pessoas trazem consigo para dentro das organizações. De acordo com Davel e Vasconcelos (1997), as condições materiais do presente, bem como a forma como as estruturas do trabalho e das ocupações são construídas socialmente, dependem da influência da história de cada sociedade. 
Desse modo, considerar a história da configuração sociocultural de cada país é requisito fundamental para a compreensão de como os traços culturais constituem componentes importantes das identidades sociais e se inserem no contexto dos estudos organizacionais. Barbosa (1996) sugere que as contribuições da antropologia ao entendimento das práticas administrativas podem ir além das questões tratadas no âmbito do conceito de cultura organizacional. Para tanto, torna-se imperativo compreender as relações mantidas pelas organizações com a sociedade circundante. Diversos autores (Barbosa, 1996; Freitas, 1997; Prestes Motta e Caldas, 1997) sugerem a necessidade de entendimento dos aspectos culturais nas organizações, mediante a compreensão das raízes, formação e transformação das características da cultura nacional.

O tratamento desse tema suscita outra questão relevante: qual a influência da cultura nacional em um contexto que muitos acreditam ser cada vez mais dominado por padrões universais de homogeneização? Em relação a essa questão, duas perspectivas básicas podem ser identificadas na literatura especializada: a da hipótese da convergência cultural (culture-free hypothesis) e a da hipótese da divergência cultural (culture-bound hypothesis). Na primeira, defende-se a existência de princípios estruturais e administrativos universais, com origem em países econômica e tecnologicamente mais avançados, que independem do contexto cultural das outras sociedades em que são aplicados, levando à crença de que práticas administrativas cada vez mais próximas tornariam as organizações e, por via de conseqüência, as sociedades cada vez mais parecidas. Na segunda, argumenta-se que contextos nacionais diferentes influenciam o modo como as organizações são estruturadas e o comportamento de seus membros, existindo, portanto, correlação entre cultura nacional e formas de gestão organizacional (Hickson e McMillan, 1981; Miller, 1987; Tayeb, 1994; Aidar, et al., 1995).

Nesse contexto, Barbosa (1996) destaca que ao se considerar a dimensão cultural no âmbito das organizações, abre-se caminho, por um lado, para a discussão em maior profundidade do tema; por outro, pode-se desmitificar a idéia de que o mundo dos negócios é movido unicamente por uma lógica pragmática, de caráter exclusivamente racional-instrumental, em direção à homogeneização das estruturas e sistemas organizacionais.

\section{Características da Cultura Brasileira}

Uma vez que se considera a necessidade de incorporar a lógica cultural societária aos estudos organizacionais, torna-se relevante discutir a existência ou não de traços culturais que seriam comuns à sociedade brasileira. A evidência da diversidade cultural na sociedade brasileira é flagrante, em face de sua formação histórica, de sua multiplicidade racial e do reconhecimento da existência de características culturais regionais significativas. Bosi (1992) reconhece essa heterogeneidade e atenta para o fato de que a admissão de seu caráter plural é importante para a efetiva compreensão da sociedade nacional. Apesar dessa diversidade, não se pode dizer que o Brasil seja um país culturalmente caótico, já que "o mapa das subculturas e interculturas do Brasil calca-se sobre as linhas de força da nossa divisão social" (Bosi, 1992, p. 15). O pluralismo brasileiro, que se expressa nas características regionais da cultura, "se soma na identidade nacional que faz do brasileiro, apesar das peculiaridades regionais, um só brasileiro" (Diégues Júnior, 1978, p. 11). A tendência de apropriação de manifestações culturais e sua subseqüente transformação em símbolos de identidade nacional é fenômeno peculiar brasileiro, que ocorre em nível de intensidade maior do que em outros países (Oliven, 1990).

Assim, a partir da compreensão da história de configuração sociocultural da sociedade brasileira, torna-se possível levantar características culturais, mais ou menos homogêneas, tais como as seguintes: personalismo, protecionismo, aversão à incerteza, formalismo, jeitinho, receptividade ao estrangeiro e orientação para o curto prazo (vide Quadro 1). Vale assinalar que esses traços culturais não são absolutamente inalteráveis; nem sempre existiram e não são necessariamente imutáveis, mas se formaram historicamente, inscritos nas estruturas sociais e no inconsciente coletivo. Além disso, nenhum conjunto de características culturais, por mais completo que possa ser, possibilita ampla compreensão de uma cultura (Herskovits, 1963). 
Quadro 1: Principais Características Culturais Nacionais

\begin{tabular}{|c|c|}
\hline Características culturais brasileiras & Indicadores \\
\hline Personalismo & $\begin{array}{l}\text { Favoritismo } \\
\text { Paternalismo } \\
\text { Ênfase nas relações pessoais } \\
\text { Apropriação do público pelo privado } \\
\text { Igualdade moral e não jurídica }\end{array}$ \\
\hline Protecionismo & $\begin{array}{l}\text { Postura de espectador } \\
\text { Orientação pela autoridade externa } \\
\text { Governo como princípio unificador } \\
\text { Transferência de responsabilidade }\end{array}$ \\
\hline Aversão à incerteza & $\begin{array}{l}\text { Necessidade de regras } \\
\text { Evitar o conflito } \\
\text { Afeição à paz e à ordem } \\
\end{array}$ \\
\hline Formalismo & $\begin{array}{l}\text { Regras sem fundamentação nos costumes } \\
\text { Diferença entre a lei e a conduta concreta } \\
\text { Exagerado apego às leis } \\
\text { Legalismo }\end{array}$ \\
\hline Jeitinho & $\begin{array}{l}\text { Burla a uma norma preestabelecida } \\
\text { Fazer vista grossa } \\
\text { Arranjar um padrinho } \\
\text { Flexibilidade } \\
\text { Rapidez } \\
\text { Improvisação }\end{array}$ \\
\hline Receptividade ao estrangeiro & $\begin{array}{l}\text { Receptividade a outras raças } \\
\text { Hospitalidade } \\
\text { Gosto pelo que vem de fora } \\
\text { Importações de técnicas } \\
\text { Valorização maior do que vem de fora }\end{array}$ \\
\hline Orientação para o curto prazo & Ênfase no planejamento de curto prazo \\
\hline
\end{tabular}

Fonte: literatura especializada sobre a cultura brasileira (vide Nota 1)

É notório o fato do Brasil ter recebido forte herança de Portugal, que possuía, como traço marcante, a cultura da personalidade: uma forma radical de individualismo, que se reflete no princípio hierárquico, capaz de abrir brechas e de assimilar novas idéias sem transformar seu tradicional modo de pensar e de agir (Gomes, 1990; Holanda, 1995). A concretização dessa característica pode ser observada ao longo da história brasileira, a partir, inicialmente, da noção de cunhadismo. O velho uso indígena de incorporar estranhos à sua comunidade tornou-se prática comum para os que aqui chegavam, estabelecendo laços que aparentavam o estranho com os membros do grupo, possibilitando ao colonizador utilizar essa relação aparente de parentesco para convencer os índios a trabalharem na extração do pau-brasil. Outra forma de se notar esse traço, é por meio do domínio que o senhor de engenho exercia com base em sentimentos afetivos que, simultaneamente, minimizavam e reforçavam a sua autoridade. Ainda mais, no início do período republicano, a figura do coronel estabelece o seu domínio, também por meio do afeto e da violência (Gomes, 1990; Ribeiro, 1995; Prestes Motta e Alcadipani,1999).

O tipo de domínio rural resultante do processo de colonização portuguesa e o papel central das relações familiares deram origem ao princípio patriarcal de autoridade, no Brasil. As unidades produtiva e familiar eram organizadas ao mesmo tempo e de maneira similar pelo senhor de engenho, que estendia os seus domínios para além de suas fronteiras, influenciando gerações 
sucessivas. A contrapartida psicológica a esse que se tornou um dos suportes da sociedade colonial consistia na evidência de que o ambiente doméstico acompanha o indivíduo, mesmo quando ele se encontra fora dele: o privado transbordando para o público. A existência de escravos, das plantações e das casas, e a constante presença de agregados contribuíam para aumentar a autoridade do paterfamílias, tornando o quadro familiar poderoso, mesmo fora do recinto doméstico. Em consequiência, a noção de entidade privada precede sempre à da pública, prevalecendo as preferências fundadas em laços afetivos, marcando a sociedade e a vida pública nacional (Holanda,1995).

Dessa formação histórica resulta um dos principais traços, considerado muitas vezes como a chave do caráter brasileiro, o personalismo: o magnetismo exercido pela pessoa, por meio do seu discurso ou do seu poder de ligações, com predomínio do afetivo, do não-racional e do místico, dando à inteligência um aspecto essencialmente não-racional e carregado de imaginação (Azevedo, 1971; Prates e Barros, 1997). Essa origem personalista implica que os vínculos de pessoa a pessoa venham sendo, quase sempre, mais decisivos do que qualquer tendência racionalizadora, ordenadora ou disciplinadora. Assim, a frouxidão das instituições e a sobreposição dos interesses pessoais em relação ao conjunto da sociedade acabam gerando problemas de coesão social, uma vez que cada um favorece os seus em detrimento da coletividade (Prestes Motta e Alcadipani, 1999).

Observa-se amplamente na sociedade brasileira, inclusive nas organizações burocráticas, reflexos do que foi exposto nos parágrafos precedentes. O brasileiro espera da organização hospitalidade e harmonia, não luta e competição. Espera sentir-se em casa, que a organização reproduza a família, o que se revela em facetas conhecidas do mundo social brasileiro: paternalismo, favoritismo e interações com base nos relacionamentos pessoais, em detrimento das características profissionais universais (Thiry-Cherques, 1995). A empresa funciona, portanto, como indicador da posição social e da estabilidade econômica, influenciando mais na inserção como pessoa na sociedade do que em seu papel enquanto indivíduo (Barbosa, 1996).

Uma decorrência do fato da sociedade brasileira ser fundamentada em relações pessoais é o que se denomina protecionismo. Conforme já se discutiu, o convívio na sociedade é permeado por relações afetivas, em que certas pessoas acabam exercendo forte influência sobre as outras, desenvolvendo soluções paternalistas e forte traço autoritário. Além disso, a formação da burguesia nacional parece ter acentuado essa tendência. A burguesia urbana, desde o império, desenvolveu o hábito de apelar para o governo a propósito de tudo quanto interessasse a mais de duas pessoas, pressionando o Estado a funcionar como a providência a que se recorre como sistema de amparo e proteção (Azevedo, 1971).

Como reflexo dessa orientação protecionista, pode-se identificar a postura de espectador que o brasileiro adota: esperando por soluções externas - muitas vezes esse externo é representado pelo governo ou pelo estrangeiro; funcionando de forma reflexiva, orientado pela autoridade externa. $\mathrm{O}$ centro de gravitação parece ser uma referência dominadora externa, com conseqüências negativas sobre a consciência crítica, sobre a capacidade de iniciativa e de realização por autodeterminação, gerando a transferência das dificuldades que encontra no cotidiano para as lideranças (Prates e Barros, 1997). O discurso do empresariado brasileiro, às vezes, até assume caráter liberal, mas as suas atividades e o investimento privado são concebidos como conseqüência do investimento estatal (Barbosa, 1996). Assim, a atividade empresarial, principalmente a de grande porte, não se constitui como atividade estritamente empreendedora, de natureza privada, com seus os riscos e as suas incertezas.

Outra característica, que guarda estreita relação com a anterior, é a aversão à incerteza. Em conformidade com a definição utilizada por Hofstede (1980), pode-se considerá-la o modo como os membros de determinada cultura procuram evitar a incerteza, visando à estabilidade e à previsibilidade. De acordo com a pesquisa desse autor, o Brasil é considerado um país em que essa característica está presente. As relações paternalistas, de cunho emotivo e sentimentalista, marcadas por relações antagônicas de amor e de ódio, de afeto e de violência, sobrepõem-se às posições econômico-racionais ou racionais-legais, resultando na aparente polidez das atitudes em que se evita a ofensa, o mau trato e as brigas (Prestes Motta e Alcadipani, 1999). Assim, pode-se visualizar esse traço cultural no modo como o conflito é evitado e na medida em que se mantém forte afeição pela paz e pela ordem (Prates e Barros, 
1997). No caso do surgimento de uma fonte de conflitos, cabe às relações pessoais e ao tratamento indireto formas de se evitar o combate e o enfrentamento, que poderiam levar a resultados incertos.

Muitas vezes essa procura por estabilidade se reflete no formalismo - discrepância entre as normas legalmente prescritas e as atitudes concretas dos indivíduos. Quanto maior o desejo de controlar influências externas e aumentar a previsibilidade em relação ao futuro, maior a necessidade de regras, mesmo que elas, muitas vezes, não funcionem, uma vez que garantem, pelo menos aparentemente, certo grau de segurança. Assim, a lei de origem formalista, por não se apoiar em valores ou costumes construídos na interação social pelos participantes da sociedade, estabelece uma diretriz que dificilmente consegue ser colocada em prática, tendo, no mais das vezes, pouco efeito sobre o comportamento dos indivíduos. Em consequiência, as normas deixam de ser observadas, sem que isso caracterize, necessariamente, a obrigatoriedade de sanções (Guerreiro Ramos, 1966; Riggs, 1968; Vieira, Costa e Barbosa, 1982).

A compreensão da presença marcante do formalismo no Brasil passa pelo entendimento de como a história nacional tem apresentado momentos distintos de sua integração no âmbito da história mundial: a sociedade brasileira tem sido "algo no tocante às suas condições internas, e outra distinta, quanto às suas relações externas" (Guerreiro Ramos, 1966, p. 411). Ainda de acordo com esse autor, o problema histórico do Brasil deve ser entendido sob duas formas: uma externa, voltada para o mundo e visando à inserção do país na evolução histórica mundial; e outra, particular, que articula essas mudanças aos interesses internos do país. Ele considera o formalismo como estratégia de construção nacional: em seus primórdios, o Brasil não tinha povo, seus 'construtores' mão tinham em que se inspirar, a fim de estabelecerem suas instituições formais; recorreu-se a soluções formalistas, a exemplos estrangeiros, na maioria das vezes estranhos à realidade brasileira e muito acima dos costumes da população. Nos dias atuais, o frmalismo tem sido utilizado tanto como mecanismo de manutenção quanto de transformação social, em face das pressões externas e dos arranjos de poder resultantes da dinâmica de relacionamento entre os grupos de interesse na sociedade brasileira.

O formalismo, que, portanto, provoca desconfiança quanto à validade das normas, constitui, assim, a raiz estrutural do jeitinho. "O jeitinho é sempre uma forma 'especial' de se resolver algum problema ou situação difícil ou proibida; ou uma solução criativa para alguma emergência, seja sob forma de burla a alguma regra ou norma preestabelecida, seja sob a forma de conciliação, esperteza ou habilidade" (Barbosa, 1992, p. 32). É o processo pelo qual a pessoa busca atingir objetivos, a despeito de determinações contrárias; a maneira de resolver e conseguir coisas por meio da criatividade, contornando dificuldades, conseguindo favores, fugindo da burocracia, influenciando terceiros de modo a gerar, muitas vezes, eficiência e rapidez (Vieira, Costa e Barbosa, 1982; Prestes Motta e Alcadipani, 1999).

Para se ter melhor noção do termo é necessário discutir a distinção que DaMatta (1983, 1985, 1986) apresenta entre pessoa e indivíduo, e entre casa e rua como espaços sociais. O indivíduo é o sujeito-objeto das leis universais, impessoal e anônimo, conceito que ocasiona certa igualdade entre os seres. Já a pessoa é o sujeito das relações pessoais, com história conhecida, que o diferencia dos demais. Em relação aos espaços sociais, a casa refere-se ao espaço moral, que representa a calma e a tranqüilidade, onde se é membro de uma família, com tradições - como honra e vergonha; e a rua, lugar do movimento, o mundo exterior, onde o que se vê é luta, competição e anonimato. O peculiar, no universo social brasileiro, é que essas dias características se completam, são os dois lados de uma mesma moeda. O que se perde, o que é negado em um dos espaços, obtém-se no outro. E entre as duas formas, entre a casa e a rua, entre pessoas e indivíduos, encontram-se algumas maneiras de navegação como a malandragem e o jeitinho.

Assim, o jeitinho aparece como mediador entre a lei e a pessoa, que assume essa condição a partir do descumprimento da lei. O que se pode encontrar, portanto, no convívio social, mesmo dentro das empresas, é certo grau de desrespeito às normas universais, porque o sujeito considera sua situação particular como mais importante do que a situação genérica prevista (Prestes Motta e Alcadipani, 1999). Em contrapartida, o jeitinho torna-se, muitas vezes, responsável por incrementar a flexibilidade, a rapidez, a criatividade e a improvisação na solução de problemas, gerando expressões tão características do povo brasileiro, tais como: 'quebrar um galho' e 'fazer vista grossa'. 
A receptividade ao estrangeiro também se relaciona à onipresença do formalismo na sociedade brasileira. Holanda (1995) observa que desde o descobrimento já se pode notar essa característica, uma vez que, na época, os portugueses já constituíam uma raça de mestiços, em decorrência da constante situação de conquista e reconquista de Portugal e do contato com outros povos. Tal circunstância histórica implicou na ausência de hegemonia racial em Portugal, o que impediu a emergência de forte sentimento de orgulho da raça naquele país. Aliada a essa herança portuguesa, a formação brasileira a partir de três matrizes étnicas diferentes parece ter contribuído para o surgimento desse traço cultural de alta receptividade a outros povos (Ribeiro, 1995). Cabe ressaltar, contudo, que no Brasil sempre houve a preocupação da classe dominante branca, ou branca por autodefinição, de salientar, no plano racial, sua branquitude e, no plano cultural, sua europeidade, aspirando a ser lusitana, inglesa, francesa ou norte-americana. A imitação e a admiração do estrangeiro não seriam um problema em si mesmo; o problema reside no fato de que a sua contrapartida é a rejeição do que é nacional e popular, porque impregnado da subalternidade da terra tropical e da inferioridade dos povos de cor (Ribeiro,1972).

Aos fatores socioculturais da formação nacional soma-se, de acordo com Caldas e Wood Jr. (1998), o fato do Brasil ter passado por décadas de isolamento e de políticas protecionistas. A relativamente recente inserção do país no mercado internacional gerou uma corrida frenética em busca do tempo perdido. Despreparado para a concorrência internacional e acreditando na validade universal das práticas administrativas procura-se, de forma obsessiva, o 'como deve ser feito', o que resulta na importação de modelos e de técnicas em quantidade, sem critérios adequados de avaliação de sua aplicabilidade no contexto cultural nacional.

Finalmente, a última característica em consideração neste estudo refere-se à orientação para o curto prazo. Sua raiz também encontra-se na formação colonial brasileira. De acordo com Holanda (1995), a jornada de colonização nas terras brasileiras baseou-se, essencialmente, no tipo aventureiro, para quem a relevância se encontra no objeto final e os meios intermediários são, o quanto possível, dispensáveis, uma vez que a ânsia é de prosperidade sem custo, não de trabalho sistemático. Ao tipo trabalhador, aquele que se dedica ao esforço lento e provavelmente compensador no longo prazo, cabe papel limitado, em face da dificuldade de vencer. "A exploração dos trópicos não se processou, em verdade, por um empreendimento metódico e racional, não emanou de uma vontade construtora e enérgica: fez-se antes com desleixo e certo abandono" (Holanda, 1995, p. 43). Dessa forma, a feição aventureira deu à colonização do Brasil aspecto de exploração comercial, refletida na ocupação restrita do litoral e no predomínio do rural sobre o urbano, sem se caracterizar como processo de construção de uma sociedade tipicamente agrícola.

Essa característica da dinâmica de colonização portuguesa parece estar na origem da orientação brasileira predominantemente voltada para o curto prazo. No âmbito das organizações, um dos reflexos desse traço cultural se dá na forma como o planejamento é tratado. A preocupação que as orientam, na maioria das vezes, é de horizonte temporal limitado, sendo raras as vezes em que o planejamento de longo prazo é levado a efeito. Essa visão imediatista acaba transformando o planejamento em ferramenta, diga-se de passagem inadequada, para a solução de crises. Essa tendência é agravada pela endêmica instabilidade econômica da sociedade brasileira, com períodos freqüientes de turbulência, em que a reorientação estratégica constitui necessidade amiúde, abalando os planos de maior alcance temporal.

As principais características culturais brasileiras, brevemente delineadas nos parágrafos precedentes, parecem ser marcantes, até mesmo, como elementos da identidade nacional. Como tal, é de se esperar que se manifestem nos diversos tipos de organizações, inclusive nas empresariais. Por outro lado, a visão de ciclo de vida organizacional sugere que as mudanças estruturais que ocorrem ao longo dos diferentes estágios seguem no sentido de racionalização crescente, tendendo a minimizar, portanto, a influência dos traços tradicionais da sociedade. Cabe, pois, abordar a noção de ciclo de vida organizacional, na seqüência de construção do quadro teórico de referência. 


\section{Ciclo de Vida Organizacional}

Uma das críticas que se tem dirigido aos estudos organizacionais refere-se ao predomínio de abordagens estáticas, que deixam de levar em conta a dinâmica da mudança nas organizações. Entre as diversas perspectivas alternativas à visão estática do fenômeno organizacional interessa considerar, neste estudo, a abordagem desenvolvimentista. Ao adotar essa abordagem reconhece-se que as estruturas e sistemas das organizações experimentam diversas alterações ao longo do tempo, designadas como estágios de crescimento/desenvolvimento ou ciclo de vida organizacional. $\mathrm{O}$ conceito de ciclo de vida pode ser definido de forma estrita ou de acordo com acepção mais geral: a noção estrita sugere temporalidade e seqüência de fases no processo de maturação de determinado fenômeno, a exemplo de preceitos biológicos; a mais ampla envolve, também, os processos de geração e de reprodução (O’Rand e Krecker, 1990; Machado-da-Silva, Vieira e Dellagnelo, 1992, 1998; Machadoda-Silva e Fonseca, 1995).

No presente trabalho não cabe realizar discussão aprofundada do conceito, mas, simplesmente, asseverar que se adota a visão mais ampla de ciclo de vida, partindo-se do pressuposto que a mudança de um estágio para outro implica nível crescente de complexidade e de uso da racionalidade formal no estabelecimento de relações meio-fim. Assim, considera-se que deve ocorrer declínio no nível de presença das características culturais nacionais à medida que as organizações se situem em estágios mais elaborados do ciclo de vida. "A transposição do conceito de ciclo de vida para a análise das organizações freqüentemente supõe que a mudança transcorre de acordo com um padrão previsível, seqüencial, em progressão hierárquica dificilmente revertida, indicando fases de desenvolvimento" (Machado-da-Silva e Fonseca, 1995, p. 220).

O modelo de ciclo de vida organizacional adotado neste estudo é o proposto por Machado-daSilva, Vieira e Dellagnelo $(1992,1998)$. Tal modelo, que parte da acepção mais ampla, é composto de três estágios básicos: empreendimento, formalização e flexibilização. As principais características desses estágios encontram-se descritas no Quadro 2.

Quadro 2: Características dos Estágios de Ciclo de Vida Organizacional

\begin{tabular}{|c|c|c|}
\hline Estágio de Empreendimento & Estágio de Formalização & Estágio de Flexibilização \\
\hline - estrutura organizacional fluida & $\begin{array}{l}\text { - estrutura organizacional } \\
\text { funcional }\end{array}$ & $\begin{array}{l}\text { - estrutura organizacional } \\
\text { divisionalisada e semi-autônoma }\end{array}$ \\
\hline $\begin{array}{l}\text { - regras e procedimentos } \\
\text { personalizados }\end{array}$ & $\begin{array}{l}\text { - políticas, regras e procedimentos } \\
\text { institucionalizados }\end{array}$ & $\begin{array}{l}\text { - políticas, regras e procedimentos } \\
\text { institucionalizados, mas flexíveis }\end{array}$ \\
\hline $\begin{array}{l}\text { - planejamento e coordenação } \\
\text { incipientes }\end{array}$ & $\begin{array}{l}\text { - planejamento e coordenação } \\
\text { sistemáticos }\end{array}$ & $\begin{array}{l}\text { - planejamento sistemático de } \\
\text { longo prazo }\end{array}$ \\
\hline - poder altamente centralizado & - poder relativamente centralizado & - poder descentralizado \\
\hline - ênfase em inovação e criatividade & - ênfase no conservadorismo & $\begin{array}{l}\text { - ênfase em inovação e } \\
\text { criatividade }\end{array}$ \\
\hline $\begin{array}{l}\text { - estratégia de expansão de alto } \\
\text { risco em relação ao mercado }\end{array}$ & $\begin{array}{l}\text { - estratégia de estabilidade e } \\
\text { eficiência }\end{array}$ & $\begin{array}{l}\text { - estratégia de diversificação de } \\
\text { domínio }\end{array}$ \\
\hline $\begin{array}{l}\text { informações gerenciais } \\
\text { predominantemente informais e } \\
\text { rudimentares }\end{array}$ & $\begin{array}{l}\text { - sistema de informações } \\
\text { gerenciais predominantemente } \\
\text { centralizado }\end{array}$ & $\begin{array}{l}\text { - sistema de informações } \\
\text { gerenciais predominantemente } \\
\text { descentralizado }\end{array}$ \\
\hline - formação de nicho & $\begin{array}{l}\text { - relacionamento estável com o } \\
\text { ambiente externo }\end{array}$ & $\begin{array}{l}\text { - relação adaptativa com o } \\
\text { ambiente externo }\end{array}$ \\
\hline - $\mathrm{ca}$ & & \\
\hline
\end{tabular}

Fonte: Machado-da-Silva, Vieira e Dellagnelo $(1992,1998)$.

\section{Estágio de empreendimento}

No estágio de empreendimento, a organização procura estabelecer uma estratégia viável de mercado, usualmente por meio de ensaios do tipo tentativa e erro. Para tanto, procura posicionar-se em mercados em que o nível de competitividade é menor, de modo a definir o seu nicho de atuação. 
Preocupa-se, essencialmente, com a captação e a ordenação de recursos, uma vez que se encontra bastante vulnerável às variações ambientais. A postura de adaptação reativa em relação ao ambiente implica em aproveitar as oportunidades, mediante ações empreendedoras criativas e inovadoras. Apesar de privilegiar as vendas e a produção, sua tecnologia de fabricação ainda é incipiente A estrutura organizacional é fluida, com prevalência do relacionamento interpessoal de natureza informal. $\mathrm{O}$ planejamento é não-sistemático. $\mathrm{O}$ controle das atividades realiza-se por meio da supervisão direta e o poder é altamente centralizado. A tomada de decisão é predominantemente intuitiva e as regras e os procedimentos são personalizados, normalmente na figura do fundador ou do proprietário. $\mathrm{O}$ sistema de recompensas tende a ser paternalista e os critérios de avaliação subjetivos (Miller e Friesen, 1984; Adizes, 1990; Machado-da-Silva, Vieira e Dellagnelo, 1992, 1998).

\section{Estágio de formalização}

O estágio de formalização caracteriza-se pela elaboração da estrutura e pela institucionalização de regras e procedimentos, visando a incrementar a previsibilidade e a reduzir a influência de componentes personalistas. A direção da organização é profissionalizada e as atividades de coordenação, planejamento e controle passam a ser sistemáticos. O delineamento estrutural configura-se, usualmente, como funcional. O poder é relativamente centralizado, uma vez que se admite certo grau de delegação da autoridade. A impessoalidade, o mérito e a competência orientam os sistemas de avaliação e de recompensa. Privilegia-se o processo racional de tomada de decisão, em que a análise de dados ganha proeminência sobre a improvisação e a intuição. Enfatizam-se a consistência e a durabilidade na escolha de tecnologias de fabricação, em face da preocupação primordial com a eficiência e a estabilidade. $\mathrm{O}$ relacionamento com o ambiente tende a ser estável, em função da clara definição de nichos de mercado, de objetivos e de estratégias, refletindo postura mais conservadora. $\mathrm{O}$ espaço para a inovação é limitado e a organização procura seguir os concorrentes, uma vez que tenta evitar o risco decorrente da implementação de novas estratégias empresariais (Miller e Friesen, 1984; Adizes, 1990; Machado-da-Silva, Vieira e Dellagnelo, 1992, 1998).

\section{Estágio de flexibilização}

No estágio de flexibilização, a organização alcança a maturidade e procura expandir o seu domínio em relação ao mercado. A expansão de domínio pode ocorrer mediante a diversificação de produtos, de clientes e de mercados. O investimento em atualização tecnológica, pesquisa e desenvolvimento, flexibilização da linha de produção e formação de grupos de trabalho com profissionais especializados é crucial para sustentar a estratégia de expansão de domínio. A configuração divisionalizada e semi-autônoma, estruturalmente mais maleável, confere maior autonomia aos profissionais para conceberem e cumprirem as suas atividades. $\mathrm{O}$ poder é descentralizado e considera-se, fortemente, a proatividade e a propensão ao risco na tomada de decisão, que tende a levar em conta não apenas um sistema profissional, analítico e participativo, mas, também, a intuição empresarial. Enfatiza-se a comunicação entre unidades e o sistema de recompensas tem como base, em especial, o grupo. As regras e os procedimentos, em comparação com o estágio de formalização, são mais flexíveis, não só possibilitando, mas estimulando a criatividade e a inovação sistemáticas (Miller e Friesen, 1984; Adizes, 1990; Machado-da-Silva, Vieira e Dellagnelo, 1992, 1998).

\section{A SITUAÇÃO EM ESTUDO}

O objetivo da presente pesquisa consistiu em verificar se o nível de presença das características culturais nacionais varia de acordo com o estágio do ciclo de vida organizacional em que se encontram as empresas do setor de alimentos do Estado do Paraná, Brasil, uma vez que se pressupõe que a mudança de um estágio para outro implica em nível crescente de racionalidade. Em 
face da hipótese básica de pesquisa decorrente, utilizou-se o delineamento do tipo levantamento. Essa opção demonstrou ser adequada para a análise das relações entre essas variáveis.

A fim de alcançar esse objetivo, as empresas objeto do estudo foram classificadas em diferentes grupos, com base na identificação do estágio do ciclo de vida em que se situam. O agrupamento deu-se de tal modo que as empresas de um mesmo grupo são mais parecidas entre si do que em relação às empresas dos outros grupos. A seguir, aplicaram-se os procedimentos de análise univariada e multivariada de variância para testar a diferença entre os grupos de empresas quanto à presença das características culturais nacionais, consideradas em conjunto e individualmente. A perspectiva de análise utilizada é a transversal.

A população do estudo compõe-se de organizações do setor alimentício do Estado do Paraná. A escolha desse setor decorreu de vários fatores: a) o número elevado de empresas no Estado; b) a garantia de heterogeneidade e variabilidade estrutural, uma vez que abrange empresas de diferentes idades e de diversos tamanhos; e c) a importância econômica nos contextos paranaense e nacional. Vale ressaltar que a pesquisa se restringe às empresas industriais, deixando de considerar as de produção de matérias-primas e as comerciais.

O ramo industrial do setor alimentício no Estado do Paraná era composto, em 1998, por 520 empresas com 21 empregados ou mais, assim distribuídas: 372 pequenas (21 a 100 empregados), 125 médias (101 a 500 empregados) e 23 grandes (mais de 500 empregados). Decidiu-se utilizar a amostra por adesão para todas as empresas de portes médio e grande, bem como para uma amostra casual das empresas pequenas (em face de restrições financeiras). Assim, foram consideradas 338 empresas, no total, para a aplicação da técnica de amostragem por voluntários: 190 pequenas $(56,2 \%), 125$ médias (37\%) e 23 grandes (6,8\%). Não foram incluídas as empresas com menos de 21 empregados, apesar de numerosas, em face do uso do critério de complexidade mínima.

Os dados primários foram coletados por meio de questionário enviado via correio para três dirigentes do nível estratégico de cada uma das 338 empresas integrantes da pesquisa. As perguntas do questionário foram divididas em blocos que se destinaram à caracterização do respondente, à identificação do estágio de ciclo de vida e à verificação do nível de presença dos traços culturais nacionais nas organizações objeto da investigação. A base de construção do questionário foi a escala do tipo likert de sete pontos. O período de coleta dos dados foi da segunda metade de novembro de 1999 à primeira de março de 2000 e obteve-se o total de 64 organizações respondentes, que corresponde a $18,9 \%$ das 338 empresas componentes da investigação.

Mediante o uso da técnica de análise de agrupamento (cluster analysis) foram identificados quatro grupos de empresas, que se encontram em diferentes estágios do ciclo de vida organizacional (vide Tabela 1), em conformidade com o modelo de Machado-da-Silva, Vieira e Dellagnelo (1992, 1998), referido no Quadro 2. Observa-se a ausência de um grupo correspondente ao estágio de flexibilização, uma vez que não foram encontradas empresas que agregassem as características desse estágio. No entanto, foram identificados dois grupos de empresas que se situam em estágios entretipos: empreendimento/formalização e formalização/flexibilização. Conforme observam Greenwood e Hinings (1988, p. 300), "está na natureza de qualquer tipificação que algum caso particular é admissível 'entre' tipos".

Tabela 1: Distribuição das Empresas por Estágios do Ciclo de Vida

\begin{tabular}{|lcc|}
\hline Estágio & Quantidade & \% \\
\hline Empreendimento & 13 & $20,3 \%$ \\
Empreendimento/Formalização & 14 & $21,9 \%$ \\
Formalização & 22 & $34,4 \%$ \\
Formalização/Flexibilização & 15 & $23,4 \%$ \\
\hline Total & 64 & $100,0 \%$ \\
\hline
\end{tabular}

Fonte: dados primários da pesquisa

Uma vez identificados os quatro grupos de empresas, procurou-se verificar se eles diferem entre si quanto à presença das características culturais nacionais em consideração nesta investigação, 
com base no uso da análise multivariada de variância. As respostas às questões utilizadas para mensurar cada característica foram agrupadas de tal modo que, para cada uma delas, passou a se ter uma única medida, obtida a partir da média das respostas (vide Tabela 2).

Cabe ressaltar que a característica protecionismo foi subdividida em duas: postura de espectador e orientação pela autoridade externa. Embora ambas refiram-se o mesmo traço da cultura brasileira, revelam aspectos distintos e complementares da característica, que parecem ser relevantes na análise das organizações. Como ressaltam Prates e Barros (1997), de um lado observase a postura de espectador nos brasileiros, que esperam por soluções externas, até mesmo milagrosas ou salvadoras, para os seus problemas. De outro, verifica-se a existência de uma referência dominadora externa, que acaba se traduzindo em orientação pela autoridade externa e certo gosto pela dependência em relação àqueles considerados superiores (Barbosa, 1996).

A característica receptividade também foi analisada a partir de dois aspectos: a receptividade positiva relaciona-se aos aspectos positivos desse traço cultural, representando a procura incessante das organizações por novidades na área administrativa, o que revela consciência da necessidade de modernização e atualização constantes; já a receptividade negativa refere-se à admiração e ao temor, às vezes inexplicáveis, que as empresas brasileiras têm em relação aos concorrentes estrangeiros. Desse modo, os dois aspectos demonstram a presença da receptividade ao estrangeiro nas organizações - o primeiro, revelando algo inerente à própria natureza organizacional; o segundo, mais propriamente resultante da formação sociocultural do país.

No tratamento dos dados, realizou-se, primeiramente, a análise multivariada de variância para testar a diferença entre os grupos, considerando, de forma conjunta, todos os traços culturais em investigação: personalismo, postura de espectador, orientação pela autoridade externa, aversão à incerteza, formalismo, jeitinho, receptividade negativa, receptividade positiva e orientação para o curto prazo. Tal procedimento permitiu verificar se os grupos em distintos estágios do ciclo de vida diferem entre si, no que concerne ao nível de presença dessas características.

Tabela 2: Descrição das Características Culturais por Estágios do Ciclo de Vida

\begin{tabular}{|llccccc|}
\hline $\begin{array}{l}\text { Manova: Wilks } \\
\mathbf{p}=\mathbf{0 , 0 0 1}\end{array}$ & $\begin{array}{c}\text { Empreendi- } \\
\text { mento }\end{array}$ & $\begin{array}{c}\text { Empreendi- } \\
\text { mento/For- } \\
\text { malização }\end{array}$ & $\begin{array}{c}\text { Formali- } \\
\text { zação }\end{array}$ & $\begin{array}{c}\text { Formaliza- } \\
\text { ção/Flexi- } \\
\text { bilização }\end{array}$ & $\begin{array}{c}\text { Univariate } \\
\text { F-tests }\end{array}$ \\
\hline Personalismo & média & 4,01 & 3,71 & 3,21 & 3,10 & $\mathrm{~F}=5,8130$ \\
& média & 4,87 & 0,39 & 0,72 & 0,69 & $\mathrm{p}=0,0020$ \\
\hline Protecionismo/ & $d p$ & 1,37 & 3,94 & 3,76 & 3,42 & $\mathrm{~F}=1,7130$ \\
espectador & média & 3,55 & 1,13 & 1,14 & 1,10 & $\mathrm{p}=0,1740$ \\
\hline Protecionismo/ & $d p$ & 0,98 & 3,90 & 4,26 & 4,46 & $\mathrm{~F}=3,9722$ \\
autoridade & média & 4,36 & 4,99 & 0,52 & 0,58 & $\mathrm{p}=0,0120$ \\
\hline Aversão à incerteza & $d p$ & 0,90 & 0,46 & 4,37 & 4,18 & $\mathrm{~F}=0,4605$ \\
& média & 3,63 & 2,58 & 3,50 & 0,95 & $\mathrm{p}=0,7110$ \\
\hline Formalismo & $d p$ & 0,99 & 0,63 & 0,80 & 2,68 & $\mathrm{~F}=4,1485$ \\
& média & 3,76 & 3,29 & 3,36 & 3,17 & $\mathrm{p}=0,0100$ \\
\hline Jeitinho & $d p$ & 1,49 & 0,96 & 0,89 & 1,04 & $\mathrm{p}=0,7467$ \\
& média & 3,81 & 3,44 & 2,88 & 3,44 & $\mathrm{~F}=1,0530$ \\
\hline Receptividade/ & $d p$ & 1,86 & 1,32 & 1,09 & 1,94 & $\mathrm{p}=0,3760$ \\
negativa & média & 2,36 & 2,58 & 3,86 & 3,99 & $\mathrm{~F}=3,3976$ \\
\hline Receptividade/ & $d p$ & 1,32 & 1,81 & 1,46 & 2,41 & $\mathrm{p}=0,0240$ \\
positiva & média & 5,90 & 5,16 & 4,51 & 3,94 & $\mathrm{~F}=7,7353$ \\
\hline Orientação para & $\mathrm{o}$ & 0,93 & 1,23 & 1,21 & $\mathrm{p}=0,0000$ \\
\hline curto prazo & $d p$ & 1,09 & & & &
\end{tabular}

Fonte: dados primários da pesquisa

Os resultados contidos na Tabela 2 possibilitam que se verifique a corroboração parcial da hipótese básica de pesquisa de que os grupos de empresas, que se situam em estágios distintos do ciclo de vida, revelam diferenças quanto ao nível de presença dos traços culturais em estudo. $\mathrm{O}$ teste 
univariado de variância enriquece a análise, uma vez que auxilia na visualização de quais são os atributos que mais contribuem para essa diferenciação. Pode-se observar que os grupos diferem entre si nas seguintes características: personalismo, protecionismo/orientação pela autoridade externa, formalismo, receptividade positiva e orientação para o curto prazo. Já no que concerne às características protecionismo/postura de espectador, aversão à incerteza, jeitinho e receptividade negativa não foram encontradas diferenças significativas entre os grupos.

$\mathrm{Na}$ seqüência, discorre-se sobre cada característica, considerada individualmente, de maneira a levar em conta a sua especificidade. A discussão de cada característica parte da hipótese de pesquisa formulada para cada uma delas. Infelizmente não há espaço disponível para apresentar as tabelas com as análises univariadas e multivariadas de variância dos diversos aspectos que compõem cada característica cultural. De qualquer sorte, se o leitor estiver interessado no acesso a essas tabelas basta entrar em contato com os autores do presente trabalho.

\section{Personalismo}

Hipótese: As organizações que se encontram em estágios mais elaborados do ciclo de vida revelam menor nível de presença da característica personalismo.

A análise da característica personalismo denota que os grupos apresentam diferenças estatísticas significativas, conforme se pode visualizar na Tabela 2. A tendência que se observa corrobora a hipótese de que as empresas que se encontram em estágios mais elaborados do ciclo de vida revelam menor presença dessa característica. No entanto, mesmo nas organizações localizadas no estágio de empreendimento, onde sua presença é maior, a média situa-se em torno de quatro.

Pode-se especular um pouco sobre essa e algumas outras médias relativamente baixas, que serão observadas na sequiência da análise de cada uma das características culturais. Entre outras possibilidades, é provável que as variáveis tamanho e idade ofereçam alguma explicação. Infelizmente o número de empresas integrantes de cada um dos quatro grupos é relativamente pequeno, impossibilitando essa verificação. Fica, pois, o registro de que essas variáveis deveriam ser consideradas em estudos da mesma natureza, que possam vir a ser realizados no futuro.

Os aspectos desse traço cultural visaram a identificar, em especial, a presença do favoritismo e do paternalismo nos processos de contratação e de promoção nas empresas. Os resultados demonstram que as empresas em estágios mais complexos se baseiam mais em requisitos do mérito e da competência, enquanto as empresas dos estágios menos elaborados adotam, em maior grau, critérios com base nas relações pessoais, principalmente da parte do dirigente-proprietário.

$\mathrm{Na}$ verdade, nos dois primeiros grupos relacionados na Tabela 1 (empreendimento e empreendimento/formalização) a administração das empresas pode ser definida como familiar. As normas de funcionamento são personalizadas e centralizadas no dirigente-proprietário, o que se reflete na importância atribuída às relações pessoais. O dirigente-proprietário administra seu negócio como em uma grande família, enfatizando as relações pessoais e convertendo a confiança pessoal no principal critério para a promoção e para a contratação de empregados, o que está em consonância com as análises de Prates e Barros (1997) e de Prestes Motta e Alcadipani (1999). Nesse tipo de organização, em que a formalização de normas e procedimentos é baixa e as relações personalistas sobrepõem-se às profissionais, procura-se criar um ambiente em que os conflitos são minimizados e se estimula a hospitalidade e a harmonia, confirmando a descrição de Thiry-Cherques (1995), às vezes com custos pessoais muito elevados para os empregados.

Nas organizações situadas nos estágios mais elaborados do ciclo de vida, a formalização de regras e procedimentos propicia a diminuição do personalismo. Observa-se maior grau de dissociação entre direção e propriedade, resultando em administração mais profissional. Os critérios pessoais de promoção e de contratação são substituídos por critérios com base no mérito e na competência, sobretudo com suporte na experiência e formação profissionais. Pode-se dizer que os ideais de civilidade sobrepõem-se aos ideais de cordialidade, minimizando a manifestação do personalismo, como afirmam Avelino Filho (1990) e Holanda (1995). 
Os resultados parecem confirmar, portanto, que, na própria medida em que a figura do dirigente-proprietário perde importância e as regras e procedimentos se tornam sistemáticos, diminui o espaço para a ocorrência do favoritismo e do paternalismo no contexto organizacional. Nos estágios mais elaborados do ciclo de vida, a confiança pessoal e os laços de amizade cedem lugar, em certo grau, ao profissionalismo.

\section{Protecionismo}

Hipótese: As organizações que se encontram em estágios mais elaborados do ciclo de vida revelam menor nível de presença da característica protecionismo.

O traço cultural protecionismo/postura de espectador procura evidenciar a posição predominantemente passiva dos brasileiros que, diante de situações difíceis, preferem esperar por soluções externas para os seus problemas. Assim, procurou-se avaliar se, em momentos de crise, as organizações em estudo atribuem aos problemas internos - em face de pressões ambientais externas a sua situação, tratando de encontrar soluções próprias ou se elas associam as suas dificuldades exclusivamente aos problemas externos, preferindo adotar postura não-ativa, esperando a situação se resolver por si só para, apenas então, retomar os seus investimentos.

Conforme se pode visualizar na Tabela 2, não foram encontradas diferenças estatísticas significativas entre os grupos de empresas em relação a essa característica cultural: as médias variaram de 3, 42 a 4, 41. Apesar da hipótese ser refutada, nota-se a tendência das empresas, situadas nos estágios mais elaborados do ciclo de vida, apresentarem menor grau de presença dessa característica.

Embora não sejam significativos estatisticamente, os resultados sugerem que, nas empresas localizadas nos estágios mais complexos, demanda-se maior proatividade organizacional, em face das pressões do ambiente competitivo - em situações difíceis realizam-se investimentos como forma de retomar o crescimento. Além disso, a própria configuração estrutural, crescentemente profissional e menos centralizada, tende a minimizar ou a eliminar a reatividade, estimulando os membros da empresa a adotarem postura de procura incessante de soluções. Talvez estudos que considerem maior número de organizações, de diferentes ramos e setores, possam contribuir para a avaliação mais adequada desse traço cultural.

Como já se ressaltou, a característica cultural protecionismo foi dividida em dois aspectos, para efeito de análise na presente investigação. $\mathrm{O}$ segundo aspecto aqui considerado se relaciona à referência dominadora que a autoridade externa representa para as organizações brasileiras. Focalizou-se, portanto, como as soluções visualizadas para os problemas e o comportamento dos membros da empresa são direcionados para e pelas pessoas de fora, revelando o protecionismo enquanto transferência de responsabilidade e orientação pela autoridade externa.

Observa-se na Tabela 2, que a diferença entre os grupos é estatisticamente significativa. No entanto, a tendência que se verifica é a de aumento da presença desse aspecto nas empresas situadas nos estágios mais elaborados do ciclo de vida. Esse resultado, que leva a refutar a hipótese de pesquisa, parece encontrar explicação quando se consideram os componentes desse aspecto do traço cultural.

Ao se considerar esse aspecto de um ponto de vista estritamente interno à empresa, em que se avalia o grau em que os subordinados procuram a orientação de seus superiores, observam-se médias superiores a quatro em todos os grupos, com clara tendência de ascensão nos estágios mais complexos do ciclo de vida. Na verdade, a busca por orientação do superior hierárquico dentro da empresa pode ser encarada como evidência de profissionalismo nos estágios mais elaborados do ciclo de vida, uma vez que ganha maior força a responsabilidade do grupo, em que o dirigente parece ser visto mais como liderança do que como superior hierárquico autoritário, de base paternalista.

Além disso, os resultados sugerem que os dirigentes das organizações situadas nos estágios mais complexos do ciclo de vida requerem a presença mais efetiva do governo, enquanto protetor e incentivador das empresas nacionais. Esse achado parece revelar o governo como forte referência 
externa para as organizações nacionais que, como notou Barbosa (1996), concebem o investimento privado relacionado ao investimento estatal. O menor grau de presença desse componente nas empresas localizadas nos estágios menos elaborados do ciclo de vida, talvez se explique pela evidência de que a concorrência se verifica em nível mais local ou regional. As empresas nos estágios mais elaborados que, muitas vezes, competem com as multinacionais, acabam associando a sua atuação com a própria atuação do governo brasileiro, não encarando a atividade empresarial como atividade estritamente de natureza privada. Desse modo, parece persistir a particularidade da elite brasileira, que desde os seus primórdios apelava para o governo por considerar o Estado como força de amparo e de proteção (Azevedo, 1971; Holanda, 1995).

Por fim, o último componente desse aspecto diz respeito à delegação da solução de problemas a consultores externos. Em relação a esse componente, as médias foram baixas em todos os grupos. Os resultados encontrados e a análise decorrente sugerem que a investigação do protecionismo nas organizações deve levar em conta os seus diversos aspectos de forma mais inclusiva. Ao que tudo indica, só pesquisas mais detalhadas desses aspectos poderão trazer maior entendimento desse traço cultural nos estudos organizacionais.

\section{Aversão à incerteza}

Hipótese: As organizações que se encontram em estágios mais elaborados do ciclo de vida revelam menor nível de presença da característica aversão à incerteza.

O nível de presença do traço cultural aversão à incerteza não apresenta diferenças estatísticas significativas entre os grupos de empresas classificadas nos diferentes estágios do ciclo de vida, conforme se pode verificar na Tabela 2. Em todos os grupos a presença dessa característica se mostrou similar, com médias pouco superiores a quatro. Assim, essa hipótese de pesquisa é refutada.

A explicação possível é a de que, nos estágios menos elaborados do ciclo de vida, em que a presença do personalismo é mais evidente, os questionamentos e os conflitos entre empregados são considerados como prejudiciais à paz e à ordem na empresa. $\mathrm{O}$ dirigente-proprietário, que concentra o poder em suas mãos, tende a encarar esse tipo de manifestação como questionamento à sua autoridade. Nesse sentido, as relações paternalistas acabam gerando um ambiente de paz e de ordem, mesmo que a harmonia seja aparente, o que se reflete no evitamento do conflito. Já em empresas situadas nos estágios mais complexos do ciclo de vida, a tendência em direção ao evitamento do conflito, à paz e à ordem parecem decorrer da maior descentralização da autoridade e, principalmente, do grau maior de profissionalização dos membros.

\section{Formalismo}

Hipótese: O nível de presença do formalismo é maior em empresas que se situam no estágio de formalização do que naquelas que se localizam nos demais estágios do ciclo de vida.

O formalismo apresenta-se em graus diferentes nos diversos estágios, como se demonstra na Tabela 2. Observa-se que essas diferenças se confirmam estatisticamente, mas percebe-se que as médias são baixas para todos os grupos de empresas, qualquer que seja o estágio de ciclo de vida considerado. Apesar da média do grupo no estágio de formalização ser maior do que as médias dos grupos nos estágios entre-tipos, ela é menor do que a média do grupo no estágio de empreendimento, o que implica em refutar a hipótese de pesquisa.

$\mathrm{Na}$ avaliação sobre o aspecto da existência de normas irreais, que não são cumpridas ou sequer são conhecidas pelos empregados, as empresas apresentam médias baixas, inferiores a quatro para todos os grupos. Entretanto, elas se mostraram mais elevadas nos estágios puros tanto de empreendimento como de formalização e menores nos estágios entre-tipos: empreendimento/formalização e formalização/ flexibilização. Tal resultado pode ser decorrência da própria combinação das características para as classificações entre-tipos. 
A maior presença dessa característica no estágio de formalização, em relação aos dois estágios entre-tipos, é facilmente compreensível, uma vez que é praticamente lugar comum a maior institucionalização das normas e procedimentos, nessa fase. Nesse sentido, cabe observar que essa maior propensão à formalização pode ser negativa, gerando regras que não refletem o dia a dia organizacional; preocupados com a estabilidade e com a sistematização do comportamento, os dirigentes podem acabar impondo regras e normas excessivas e, até, irreais. Já no estágio de empreendimento, em que o resultado foi, de certo modo surpreendente, a explicação para a média ser, relativamente, a mais alta pode estar relacionada à centralização do poder e ao nível do empreendedorismo organizacional. É bastante provável que o não-cumprimento das regras decorra de sua informalidade, uma vez que, usualmente, são estabelecidas verbalmente pelo próprio dirigente-proprietário.

Em contraste, quando se analisa o aspecto que se refere a quanto as regras e os procedimentos revelam sobre o funcionamento das empresas, as médias encontradas foram elevadas. Assim, de acordo com os dirigentes, as regras e os procedimentos dizem pouco sobre o funcionamento das organizações. Tal resultado sugere baixa correspondência entre as normas e o dia a dia do funcionamento organizacional. No estágio de empreendimento, tal achado pode ser explicado pelo baixo grau de formalização, dificultando a correspondência entre as normas e o cotidiano das empresas. Já nos estágios de empreendimento/formalização e formalização, a presença desse fenômeno decorre, provavelmente, da preocupação com a institucionalização de regras e procedimentos, o que deve refletir a prevalência de um sistema formalístico. Por fim, o grupo de empresas no estágio de formalização/flexibilização apresentou a menor média para esse aspecto do traço cultural, sugerindo que a flexibilidade provavelmente minimiza a tendência observada para os outros grupos.

\section{Jeitinho}

Hipótese: As organizações que se encontram em estágios mais elaborados do ciclo de vida revelam menor nível de presença da característica jeitinho.

Em todos os grupos de empresas a média ficou abaixo de quatro, revelando a percepção dos dirigentes de que o jeitinho se encontra pouco presente, conforme se pode verificar na Tabela 2 . Além disso, os grupos não se diferenciam estatisticamente de maneira significativa. Tais resultados implicam em refutar a hipótese de pesquisa para essa característica cultural. No entanto, é importante tratar de alguns aspectos desse traço cultural, na sequiência.

Quando se analisa o aspecto concernente à maneira como as empresas lidam com as normas e as imposições ambientais, observa-se a tendência de diminuição ainda maior da presença do jeitinho. Por outro lado, quando se avalia a ocorrência de situações de improviso dentro da organização, verificam-se médias maiores nos grupos de empresas que se situam nos estágios de empreendimento e de formalização/flexibilização.

Nos grupos que se situam nos dois estágios menos elaborados do ciclo de vida organizacional encontram-se evidências de que as empresas, em face de sua necessidade de sobrevivência, enfatizam a flexibilidade, utilizam efetivamente a improvisação e, até mesmo, chegam a burlar normas e regulamentos. Já no estágio de formalização, o maior nível de profissionalização e a maior impessoalidade dos relacionamentos sugerem a sobreposição das leis universais e anônimas sobre as relações pessoais. Assim, a presença do jeitinho tende a ser menor do que nos dois grupos de empresas que se localizam nos estágios menos complexos do ciclo de vida. Finalmente, as empresas que integram o grupo no estágio de formalização/flexibilização parecem ter institucionalizado certo grau de flexibilidade, de tal maneira que o jeitinho se manifesta por meio de sua faceta menos questionável: o modo de resolver um problema não assume a forma de burla à norma, mas de conciliação, habilidade e criatividade para lidar com as situações difíceis. 


\section{Receptividade}

Hipótese: As organizações que se encontram no estágio de empreendimento revelam a presença de receptividade ao estrangeiro sem justificativa técnica, enquanto as organizações que se situam nos estágios mais elaborados do ciclo de vida revelam, de forma crescente, a presença de receptividade ao estrangeiro como possibilidade de incremento à competência técnica.

Outra característica cultural que acabou sendo dividida com o objetivo de enriquecimento analítico foi a receptividade ao estrangeiro. Inicialmente considerou-se o contato das organizações com as empresas estrangeiras, revelando a preocupação, de certo modo justificada, com a modernização, o que se denominou como receptividade positiva. $O$ segundo aspecto desse traço cultural, o qual se denominou como receptividade negativa, refere-se à reação dos dirigentes diante das empresas estrangeiras, geralmente de medo ou de sentimento de inferioridade ou de admiração, muitas vezes sem justificativa concreta.

No aspecto da receptividade positiva, verificada aqui sob o ponto de vista do contato com as multinacionais e as suas técnicas administrativas, observa-se que os quatro grupos de empresas diferem entre si, de maneira estatisticamente significativa, conforme se demonstra na Tabela 2. A tendência é de intensificação desse aspecto nas empresas situadas em estágios mais elaborados do ciclo de vida, embora as médias tenham sido inferiores a quatro. Na verdade, trata-se do aspecto mais 'consciente' da receptividade, revelando mais a preocupação com a modernização do que medo ou fascínio injustificado. A necessidade de atualização constante por parte dessas empresas, que se reflete na procura de novas abordagens e práticas da administração, decorre não apenas de suas estruturas mais complexas, mas também do nível dos concorrentes que têm de enfrentar, que muitas vezes inclui empresas estrangeiras.

No que concerne à receptividade negativa procurou-se avaliar em que medida os dirigentes visualizam as empresas estrangeiras como ameaça por pressuporem que elas são efetivamente melhores. Torna-se importante ressaltar que essa questão não se relaciona simplesmente com o fato dos dirigentes entenderem as empresas estrangeiras como ameaça, justificável pois são concorrentes reais ou potenciais, mas pela assertiva temerosa de que elas são melhores e oferecem produtos de melhor qualidade - o que nem sempre é verdadeiro. Além disso, esse temor envolve também a noção de que é praticamente impossível chegar ao nível das empresas estrangeiras, quando elas são efetivamente melhores. Observa-se, na Tabela 2, que os grupos não apresentaram diferenças estatísticas significativas quanto a esse aspecto.

Os resultados encontrados para a característica cultural receptividade como um todo, isto é, considerando os dois aspectos analisados, revelam que nas empresas situadas nos estágios de empreendimento e empreendimento/formalização a receptividade aparece muito mais como negativa: a admiração e o medo, muitas vezes sem justificativa, dos dirigentes em relação às empresas estrangeiras. Essa percepção é, por um lado, ingênua (baseada na crença de que o que vem de fora é necessariamente melhor); por outro, demonstra baixa capacidade de iniciativa e de realização por autodeterminação. Já nos grupos de empresas dos estágios de formalização e formalização/flexibilização verifica-se que, na própria medida em que as organizações aumentam o seu grau de profissionalização, elas passam a ver as novidades importadas e, até mesmo as pessoas procedentes de outros países, de modo mais positivo: como possibilidade de incremento em sua competência técnica.

\section{Orientação para o curto prazo}

Hipótese: As organizações que se encontram em estágios mais elaborados do ciclo de vida apresentam menor nível de orientação para o curto prazo.

Observam-se diferenças estatísticas significativas entre os grupos de empresas, no que se refere a essa característica cultural. É clara a tendência de diminuição da presença desse traço nas 
organizações situadas nos estágios mais elaborados do ciclo de vida, o que corrobora a hipótese de pesquisa. Configura-se que as empresas tendem a abandonar gradualmente a estrita orientação de curto prazo, passando a atuar, também, com horizontes temporais de médio e longo prazos. Explicase o praticamente óbvio de que a ênfase na orientação de curto prazo no estágio de empreendimento decorre da necessidade de sobrevivência, constantemente imediata, de organizações ainda incipientes.

\section{CONSIDERAÇÕES FINAIS}

A fim de proporcionar algumas evidências adicionais sobre o fenômeno organizacional no Brasil, procurou-se, no presente trabalho, avaliar a presença de características culturais nacionais em empresas industriais que se encontram em diferentes estágios do ciclo de vida. $\mathrm{O}$ constructo subjacente é a racionalidade formal, em face do pressuposto de que se verifica a racionalização crescente das organizações à medida que elas se movimentam de um estágio do ciclo de vida para outro, o que tende a minimizar o nível de influência das características culturais tradicionais da sociedade brasileira.

Conforme se discutiu na análise dos dados, os resultados permitiram corroborar que os grupos de empresas nos distintos estágios do ciclo de vida organizacional diferem entre si, de modo estatisticamente significativo, quanto ao nível de presença dos seguintes traços culturais: personalismo, protecionismo/orientação pela autoridade externa, formalismo, receptividade positiva e orientação para o curto prazo. Por outro lado, não se confirmou a previsão dos autores no que se refere às características culturais que se seguem: protecionismo/postura de espectador, aversão à incerteza, jeitinho e receptividade negativa.

Tendo em vista que o estudo se restringiu a apenas um ramo, o industrial, de apenas um setor, o alimentício, de apenas um Estado, o Paraná, os resultados devem ser olhados com bastante cautela. Além disso, a investigação baseia-se na percepção tão somente dos dirigentes do nível estratégico das empresas em exame, o que, seguramente, proporciona uma visão limitada. Outros níveis e unidades organizacionais precisam ser considerados para uma análise mais abrangente. Desse modo, os achados não podem e nem devem ser olhados de forma conclusiva. O nível de generalização é restrito. Generalizações mais significativas dependem da realização de investigações mais inclusivas, com grande número de organizações, abrangendo diversos ramos e setores de atividade na sociedade brasileira.

É importante destacar que o pressuposto básico que orientou a presente pesquisa oferece um terreno rico de possibilidades. Em tempos de globalização, constitui temática da maior relevância a idéia de verificar em que medida o processo crescente de racionalização do mundo pode levar à uniformização das estruturas das organizações e dos processos de trabalho. Ainda mais: pode afetar, de maneira decisiva, a vida humana em sociedade, nas suas diversas esferas e representações. Não se deve perder de vista que a dinâmica de racionalização supõe não apenas uma teoria da produção, mas, também, uma teoria da dominação.

Assim, o que se pode depreender de mais relevante dos resultados do presente trabalho é a necessidade premente de estudos sistemáticos da convivência e mútua influência das características básicas da cultura brasileira e de um modelo racional universal, o burocrático - apesar da expectativa, talvez mais um desejo, de que esteja em franco processo a sua superação (vide Dellagnelo e Machado-da-Silva, 2000). A simbiose possível entre a sociedade nacional e a sociedade organizacional implica na relação entre dois sistemas de lógica que precisam ser considerados mais efetivamente nos estudos organizacionais brasileiros.

\section{Nota 1}

Fontes consultadas para a construção do Quadro 1 - Principais Características Culturais Nacionais: Lambert (1959); Riggs (1964, 1968); Campos (1966); Guerreiro Ramos (1966); Leite (1969); Azevedo (1971); Hofstede (1980); Vieira, Costa e Barbosa (1982); DaMatta (1983, 1985, 1986); 
Freyre (1984); Avelino Filho (1990); Gomes (1990); Serva (1990); Amado e Brasil (1991); Barbosa (1992, 1996); Aidar et al. (1995); Holanda (1995); Ribeiro (1995); Vasconcellos (1995); Machado (1996); Caldas (1997); Caldas e Wood Jr. (1997, 1998); Matheus (1997); Prates e Barros (1997); Segato (1997); Prestes Motta e Alcadipani (1999); Castor (2000).

\section{REFERÊNCIAS BIBLIOGRÁFICAS}

ADIZES, I. Os ciclos de vida das organizações. São Paulo : Pioneira, 1990.

AIDAR, M.; BRISOLA, A.; PRESTES MOTTA, F. C.; WOOD JR., T. Cultura organizacional brasileira. In: WOOD Jr., T. (Org.). Mudança Organizacional. São Paulo : Atlas, 1995.

AMADO, G.; BRASIL, H. V. Organizational behaviors and cultural context: the brazilian 'jeitinho'. International Studies of Management and Organization, v. 21, n. 3, p. 38-61, 1991.

AVELINO FILHO, G. Cordialidade e civilidade em raizes do brasil. RBCS, v. 12, n. 5, p. 5-14, 1990.

AZEVEDO, F. A cultura brasileira. 5. ed., revista e ampliada. São Paulo : Melhoramentos, EDUSP, 1971.

BARBOSA, L. O. Cultura administrativa: uma nova perspectiva das relações entre antropologia e administração. Revista de Administração de Empresas, v. 36, n. 4, p. 6-19, 1996.

O jeitinho brasileiro. Rio de Janeiro : Campus, 1992.

BOSI, A. A cultura brasileira: temas e situações. 2. ed. São Paulo : Ática, 1992.

BOWLES, M. The myth of management: direction and failure in contemporary organizations. Human Relations, v. 50, n. 7, p. 779-803, 1997.

CALDAS, M. P. Santo de casa não faz milagre: condicionantes nacionais e implicações organizacionais da fixação brasileira pela figura do 'estrangeiro'. In: PRESTES MOTTA, F. P.; CALDAS, M. P. (Orgs.) Cultura organizacional e cultura brasileira. São Paulo : Atlas, p. 7393, 1997.

; WOOD Jr., T. 'For the english to see': the importation of managerial technology in the late 20th-century Brazil. Organization, v. 4, n. 4, p. 517-534, 1997.

; WOOD Jr., T. Antropofagia organizacional. In: XXII Fncontro Anual da ANPAD (1998: Foz do Iguaçu). Anais... Foz do Iguaçu : ANPAD, CD ROM, 1998.

CAMPOS, R. O. A sociologia do jeito. In: A técnica e o riso. Rio de Janeiro : Apec, p. IX-XXVII, 1966.

CASTOR, B. V. J. O Brasil não é para amadores: estado, governo e burocracia na terra do jeitinho. Curitiba: EBEL : IBQP-PR, 2000.

DAMATTA, R. Carnavais, malandros e heróis. 4. ed. Rio de Janeiro : Zahar, 1983.

A casa e a rua. São Paulo : Brasiliense, 1985.

O que faz o brasil, Brasil? 2. ed. Rio de Janeiro : Rocco, 1986.

DAVEL, E. P. B.; VASCONCELOS, J. G. M. Gerência e autoridade nas empresas brasileiras: uma reflexão histórica e empírica sobre a dimensão paterna nas relações de trabalho. In: PRESTES MOTTA, F. P.; CALDAS, M. P. Cultura organizacional e cultura brasileira. São Paulo : Atlas, p. 94-110, 1997.

DELLAGNELO, E. L.; MACHADO-DA-SILVA, C. L. Novas formas organizacionais: onde se encontram as evidências empíricas de ruptura com o modelo burocrático de organizações? Organizações \& Sociedade, v. 7, n. 19, p. 19-34, 2000.

DIÉGUES JÚNIOR. M. Pluralismo cultural e identidade nacional. Revista de Antropologia, v. 21, p. 3-11, 1978.

FREITAS, A. B. Traços Brasileiros para uma análise organizacional. In: PRESTES MOTTA, F. P.; CALDAS, M. P. Cultura organizacional e cultura brasileira. São Paulo : Atlas, p. 38-54, 1997.

FREYRE, G. Casa-Grande e Senzala. 23. ed. Rio de Janeiro : Livraria José Olympio, 1984. 
GOMES, A. C. A dialética da tradição. RBCS, v. 5, n. 12, p. 15-27, 1990.

GREENWOOD, R.; HININGS, C. R. Organizational design types, tracks and the dynamics of strategic change. Organization Studies, v. 9, n. 3, p. 293-316, 1988.

GUERREIRO RAMOS, A. A nova ciência das organizações. Rio de Janeiro : Fundação Getúlio Vargas, 1981. 1966.

HERSKOVITS, M. Antropologia cultural. São Paulo: Mestre Jou, 1963.

HICKSON, D. J.; MCMILLAN, C. (ed.). Organization and nation: the Aston programme IV. London : Gower, 1981.

HOFSTEDE, G. Culture's consequences. Beverly Hills : Sage Publications, 1980.

HOLANDA, S. B. Raízes do Brasil. São Paulo : Companhia das Letras, 1995.

KALBERG, S. Max Weber's types of rationality: cornerstones for the analysis of rationalization processes in history. American Journal of Sociology, v. 85, n. 5, p. 1145-1179, 1980.

LAMBERT, J. Os dois Brasis. Rio de Janeiro : Instituto Nacional de Estudos Pedagógicos, Ministério da Educação e Cultura, 1959.

LEITE, D. M. O caráter nacional brasileiro. 2. ed. São Paulo : Editora Pioneira, 1969.

LIMA, E. O. Formalização e ciclo de vida organizacionais: uma apreciação teórica. In: XX Encontro Anual da ANPAD (1996: Rio de Janeiro). Anais... Rio de Janeiro : ANPAD, p. 335-353, 1996.

MACHADO, B. P. Raízes do Brasil: uma re-leitura. Estudos Brasileiros, v. 2, p. 169-193, 1976.

MACHADO-DA-SILVA, C. L.; FONSECA, V. S. Configuração estrutural da indústria calçadista de Novo Hamburgo. In: FENSTERSEIFER, J. E. (Org.). O complexo calçadista em perspectiva: tecnologia e competitividade. Porto Alegre: Ortiz, 1995, p. 217-245.

MACHADO-DA-SILVA, C. L.; VIEIRA, M. M. F.; DELLAGNELO, E. H. L. Controle organizacional: uma abordagem a partir do conceito de ciclo de vida. In: XVI Encontro Anual da ANPAD (1992: Rio Grande do Sul). Anais... Salvador : ANPAD, v. 5, p. 126-138, 1992.

; VIEIRA, M. M. F.; DELlaGNELO, E. H. L. Ciclo de vida, controle e tecnologia: um modelo para análise das organizações. Organizações e Sociedade, v. 5, n. 11, p. 77-104, 1998.

MATHEUS, T. C. Inverno social: uma discussão psicanalítica sobre o imaginário da lei no Brasil. IN: PRESTES MOTTA, F. P.; CALDAS, M. P. Cultura organizacional e cultura brasileira. São Paulo : Atlas, p. 129-142, 1997.

MILLER, D.; FRIESEN, P. H. A longitudinal study of the corporate life cycle. Management Science, v. 30, n. 10, p. 1161-1183, 1984.

MILLER, G. A. Meta-analysis and the culture-free hypothesis. Organization Studies, v. 8, n. 4, p. 309-325, 1987.

MORGAN, G. Imagens da organização. São Paulo : Atlas, 1996.

OLIVEN, R. G. Antropologia e a diversidade cultural no Brasil. Revista de Antropologia, v. 33, p. 119-139, 1990.

O'RAND, A. M.; KRECKER, M. Concepts of the life cycle: their history, meanings, and uses in the social sciences. Annual Review of Sociology, v. 16, n. 1, p. 241-262, 1990.

PRATES, M. A. S.; BARROS, B. T. O estilo brasileiro de administrar: sumário de um modelo de ação cultural brasileiro com base na gestão empresarial. In: PRESTES MOTTA, F. C.; CALDAS, M. P. Cultura organizacional e cultura brasileira. São Paulo : Atlas, p. 55-69, 1997.

PRESTES MOTTA, F. C.; CALDAS, M. P. Introdução: cultura organizacional e cultura brasileira. In: PRESTES MOTTA, F. C.; CALDAS, M. P. Cultura organizacional e cultura brasileira. São Paulo : Atlas, p. 15-21, 1997.

; ALCADIPANI, R. Jeitinho brasileiro, controle social e competição. Revista de Administração de Empresas, v. 39, n. 1, p. 6- 12, 1999.

PRESTHUS, R. The organizational society: an analysis and a theory. New York : Random House, 1962.

The organizational society - revised edition. New York: St. Martin's Press, 1978. 
QUINN, R. E.; CAMERON, K. Organizational life cycles and shifting criteria of effectiveness: some preliminary evidence. Management Science, v. 29, n. 1, p. 33-51, 1983.

RIBEIRO, D, O povo brasileiro: a formação e o sentido do Brasil. São Paulo : Companhia das Letras, 1995.

Teoria do Brasil. Rio de Janeiro : Paz e Terra, 1972.

RIGGS, F. W. A ecologia da administração pública. Rio de Janeiro : USAID, 1964. 1968.

Administração nos países em desenvolvimento. Rio de Janeiro : Fundação Getúlio Vargas,

SEGATO, R. L. Formações de diversidade: nação e opções religiosas no contexto da globalização. Série Antropologia, n. 215, 1997.

SERVA, M. Contribuições para uma teoria organizacional brasileira. Revista de Administração Pública, v. 24, n. 2, p. 10-21, 1990.

TAYEB, M. Organizations and national culture: methodology considered. Organization Studies, v. 15, n. 3, p. 429-446, 1994.

THIRY-CHERQUES, H. R. A rebeldia conservadora: aspectos da resistência à modernização nas organizações brasileiras. Revista de Administração de Empresas, v. 35, n. 1, p. 30-37, 1995.

VASCONCELLOS, J. G. M. A invenção do coronel. Vitória : EDUFES, 1995.

VIEIRA, C. A.; COSTA, F. L.; BARBOSA, L. O. O "jeitinho" brasileiro como um recurso de poder. Revista de Administração Pública, v. 16, n. 2, p. 5-31, 1982.

WEBER, M. Economia e sociedade: fundamentos da sociologia compreensiva. Brasília: Editora da UnB, 1991. 1.v. 